\title{
Presence of Cytoplasmic Factors Functional in Peroxisomal Protein Import Implicates Organelle-associated Defects in Several Human Peroxisomal Disorders
}

\author{
Martin Wendland and Suresh Subramani \\ Department of Biology, University of California, San Diego, La Jolla, California 92093-0322
}

\begin{abstract}
Cells from patients with peroxisome-deficient disorders contain membrane ghosts devoid of most matrix contents instead of normal peroxisomes indicating that the underlying molecular defects impair the import of matrix proteins into these peroxisome ghosts. Genetic heterogeneity for the molecular defects was inferred from the assignment of patients with peroxisomedeficient disorders into nine complementation groups. The aim of our studies was to analyze cell lines from six different complementation groups in a systematic manner for the presence of peroxisome ghosts, the ability to import Ser-Lys-Leu-containing proteins into peroxisome ghosts and for the presence of cytosolic factors required for peroxisomal protein import. We show that each of the cell lines analyzed contains peroxisome ghosts, but is unable to import matrix proteins as judged by a peroxisomal import assay using permeabilized cells. The addition of wild type cytosol did not restore the capacity to import matrix proteins but cytosol prepared from these cell lines was functional in stimulation of peroxisomal protein import in a heterologous system. These results implicate organelle-associated molecular defects in each of the six cell lines analyzed. (J. Clin. Invest. 1993. 92:2462-2468.) Key words: microbodies - hereditary diseases - Zellweger syndrome • biological transport • organelles
\end{abstract}

\section{Introduction}

Peroxisomes are vesicular organelles, bounded by a single membrane and found in virtually every eucaryotic cell. They harbor enzymes for a variety of important metabolic pathways (for a review, see reference 1). Peroxisomes proliferate by growth and division of preexisting organelles. Peroxisomal matrix proteins, as well as integral proteins of the peroxisomal membrane, are synthesized on free polysomes in the cytosol and are only posttranslationally imported into growing peroxisomes. The transport of proteins into the matrix of peroxisomes is directed by peroxisomal targeting signals (PTSs) ${ }^{1}$ of

Address correspondence to Suresh Subramani, Department of Biology 0322, University of California at San Diego, La Jolla, CA 92093-0322. Received for publication 1 April 1993 and in revised form 15 June 1993.

1. Abbreviations used in this paper: $\mathrm{CHO}$, Chinese hamster ovary; HPA, hyperpipecolic acidemia; IRD, infantile Refsum disease; NALD, neonatal adrenoleukodystrophy; PMP, peroxisomal membrane protein; PTS, peroxisomal targeting signal; SKL, Ser-Lys-Leu; SLO, streptolysin-O; ZS, Zellweger syndrome.

J. Clin. Invest.

(c) The American Society for Clinical Investigation, Inc.

$0021-9738 / 93 / 11 / 2462 / 07 \quad \$ 2.00$

Volume 92, November 1993, 2462-2468 which, so far, two distinct types have been elucidated. PTS1, a conserved tripeptide with the Ser-Lys-Leu (SKL) motif or a conservative variation of this sequence $(2,3)$, is found at the $\mathrm{COOH}$ terminus of $\sim 40$ peroxisomal proteins spanning the range of evolution from yeast to man (4). The second type (PTS2) was found within the amino terminal cleaved leader sequences of the two peroxisomal 3-ketoacyl-CoA thiolases ( 5 , $6)$. The signals that are responsible for the integration of proteins into the membrane of peroxisomes still await elucidation.

The importance of peroxisomes for the proper development of higher organisms is reflected by the discovery of genetically transmitted peroxisomal disorders in man (for a review, see reference 7). One class of these disorders (group A as classified in reference 7), including Zellweger syndrome (ZS), neonatal adrenoleukodystrophy (NALD), hyperpipecolic acidemia (HPA), and infantile Refsum disease (IRD), displays a generalized loss of peroxisomal functions. These disorders, also referred to as peroxisome-deficient disorders, are characterized by a deficiency in the synthesis of plasmalogens (8), impairment of $\beta$-oxidation of very long chain fatty acids (9), and defective degradation of pipecolic acid (10) and phytanic acid (11). Patients with ZS, the prototype of group A disorders, display severe neurological, hepatic, and renal abnormalities leading to death in infancy, while NALD, HPA, and IRD are clinically milder disorders with similar overlapping symptoms $(1,7)$.

Restoration of peroxisomal functions after somatic cell fusion of cell lines from patients with a generalized peroxisomal defect (ZS, NALD, HPA, and IRD) showed that nine different complementation groups exist $(12,13)$. Thus, up to nine different gene products are required for the biogenesis and/or maintenance of peroxisomes. Furthermore, since different phenotypes fall into the same complementation groups, and a single phenotype such as ZS displays genetic heterogeneity, there is no simple correspondence between phenotype and genotype (12). Cells of patients with a generalized peroxisomal defect are characterized by the absence of normal peroxisomes (14), which exist instead as membrane ghosts (15-19). Since peroxisome ghosts lack most peroxisomal matrix proteins, which are absent altogether or found in the cytosol, it has been suggested that the molecular defect resides in the inability to import matrix proteins (16). Recently, it has been shown that peroxisome ghosts of certain ZS patients are not completely devoid of matrix proteins but contain thiolase (18,20-22). Although not all of the complementation groups have been analyzed for the localization of thiolase, this suggested that the import deficiency in these peroxisomal disorders affects only certain classes of matrix proteins. Furthermore, ZS cells from two different complementation groups (groups 1 and 4 in terminology of references 12 and 23), microinjected with SKL-containing proteins were unable to import these substrates into their peroxisome ghosts (24). This provided evidence that these ZS 
cells display a deficiency in the import of matrix proteins containing the SKL-targeting signal.

In the present study, we analyzed the import of SKL-containing proteins in cells from patients from six different complementation groups in a systematic manner. We made use of our recently developed permeabilized cell system that allows assessment of peroxisomal protein import (25). One important finding of our previous studies was that peroxisomal protein import depends on cytosolic factors. Thus, we were interested in seeing whether the addition of wild type cytosol would restore peroxisomal protein import in cells from patients, and whether cytosol from cells derived from patients would stimulate peroxisomal protein import in a heterologous system.

\section{Methods}

Cell lines and cell culture. ZS fibroblasts GM00228 were obtained from the Human Mutant Cell Culture Repository (Camden, NJ). Control fibroblasts and seven cell lines from patients with peroxisome-deficient disorders were obtained from Ann and Hugo Moser (John Hopkins University, Baltimore, MD) (for classification see Table I). All human fibroblast cell lines were immortalized by transfection with pRSVSV40T and selection for foci (Gould, S. J., and S. Subramani, unpublished data). For continued cell culture, the immortalized cell lines were grown in Dulbecco's modified Eagle's medium supplemented with $10 \%$ fetal calf serum. CHO cells were grown in MEM supplemented with $10 \%$ fetal calf serum.

Preparation of cytosol. Rabbit reticulocyte lysate as obtained from the manufacturer (Promega Biotec, Madison, WI) was diluted in transport buffer (20 mM Hepes/potassium hydroxide, $\mathrm{pH} 7.3,110 \mathrm{mM}$ potassium acetate, $5 \mathrm{mM}$ sodium acetate, $5 \mathrm{mM}$ magnesium acetate, 1 $\mathrm{mM}$ EGTA, $2 \mathrm{mM}$ DTT, and $1 \mu \mathrm{g} / \mathrm{ml}$ each of aprotinin, leupeptin, and pepstatin) at a 1:2 dilution and used to reconstitute peroxisomal protein import in permeabilized cells.

Preparation of cytosol from fibroblasts grown in cell culture was performed as described (25). The protein concentration of the prepared cytosol was $\sim 5 \mathrm{mg} / \mathrm{ml}$ and showed maximum stimulation of peroxisomal protein import at $\sim 2 \mathrm{mg} / \mathrm{ml}$.

Permeabilization of cells with SLO and import assay. HSA was conjugated to a 12-amino acid peptide CRYHLKPLQSKL, to obtain the HSA-SKL conjugate, as described previously $(24,25)$.

Cells were grown on Pronectin F-coated coverslips (Protein Polymer Technologies, Inc., San Diego, CA) to confluent density. The cells were permeabilized as described previously $(25)$ with $2.0 \mathrm{U} / \mathrm{ml}$ of SLO followed by an incubation for $15 \mathrm{~min}$ in $1 \mathrm{ml}$ of cold transport buffer $\left(4^{\circ} \mathrm{C}\right)$ to ensure sufficient leakage of endogenous cytosol. The coverslips were then incubated as described (25) with transport buffer containing HSA-SKL $(50-100 \mu \mathrm{g} / \mathrm{ml})$, an ATP-regenerating system (1
$\mathrm{mM}$ ATP, $5 \mathrm{mM}$ creatine phosphate, and $20 \mathrm{U} / \mathrm{ml}$ creatine phosphokinase) in the presence or absence of externally added cytosol. After incubation for $45 \mathrm{~min}$ at $37^{\circ} \mathrm{C}$ the coverslips were rinsed in transport buffer, the cells fixed with $4 \%$ paraformaldehyde in PBS and subjected to indirect immunofluorescence to study the intracellular localization of HSA-SKL.

Immunofluorescence microscopy. Indirect immunofluorescence to study the intracellular localization of PMP70 (a peroxisomal integra membrane protein) and HSA-SKL was performed as described (25).

\section{Results}

Cells from patients with peroxisome-deficient disorders are unable to import SKL-containing proteins into their peroxisome ghosts. The recent development of a permeabilized cell system to study peroxisomal protein import in Chinese hamster ovary (CHO) cells (25) has made it feasible to study the import of proteins into peroxisome ghosts of cells displaying peroxisomal disorders. The observation that cells from Zellweger syndrome patients contain peroxisome ghosts (15-19) and that thiolase was found inside these peroxisomes (18, 20-22) suggested that import may only be impaired for certain classes of peroxisomal matrix proteins. We undertook a systematic study of eight human cell lines belonging to six different complementation groups by examining their ability to import SKL-containing proteins.

Initially, we asked whether all of the cell lines analyzed contain peroxisome ghosts. Peroxisome ghosts in cells from patients with peroxisome deficiency disorders have been detected previously by immunofluorescence, using antibodies raised against peroxisomal membrane proteins (PMP) (15). Cell fractionation studies have shown that peroxisome ghosts, like normal peroxisomes, contain integral membrane proteins of molecular sizes of $22,53,69-70$, and $140 \mathrm{kD}$, but have only low amounts of matrix proteins (16). In our studies we used rabbit anti-PMP70 antibodies to detect peroxisomes and peroxisome ghosts. The anti-PMP70 antiserum was raised against a carboxy-terminal peptide sequence of PMP70 (26), which is exposed to the cytoplasmic face of peroxisomes (Heyman, J., and S. Subramani, unpublished data). Cells from human patients with group A peroxisomal disorders (P1-P8) and a control fibroblast cell line $(C)$ were grown on coverslips, the cells were fixed with paraformaldehyde, treated with Triton X-100, and incubated with antibodies against PMP70. We found a vesicular staining pattern in the control fibroblasts, as well as in each of the patient cells (Fig. 1 and Table I), showing that each

Table I. Properties of Cells from Patients with Peroxisome-deficient Disorders

\begin{tabular}{|c|c|c|c|c|c|c|c|c|c|}
\hline Cell line & $\mathrm{C}$ & P1 & $\mathbf{P} 2$ & P3 & P4 & P5 & P6 & P7 & P8 \\
\hline Phenotype & Control & ZS & HPA & ZS & ZS & ZS & ZS & NALD & NALD \\
\hline Complementation group* & - & 1 & 1 & 2 & 3 & 4 & 4 & 6 & 8 \\
\hline PMP70 in vesicles & + & + & + & + & + & + & + & + & + \\
\hline Import of HSA-SKL into vesicles & + & - & - & - & - & - & - & - & - \\
\hline Cytosol functional in peroxisomal protein import & + & + & + & + & + & + & + & + & + \\
\hline
\end{tabular}

* Assignment by Ann and Hugo Moser in terminology of Roscher et al. (23). 

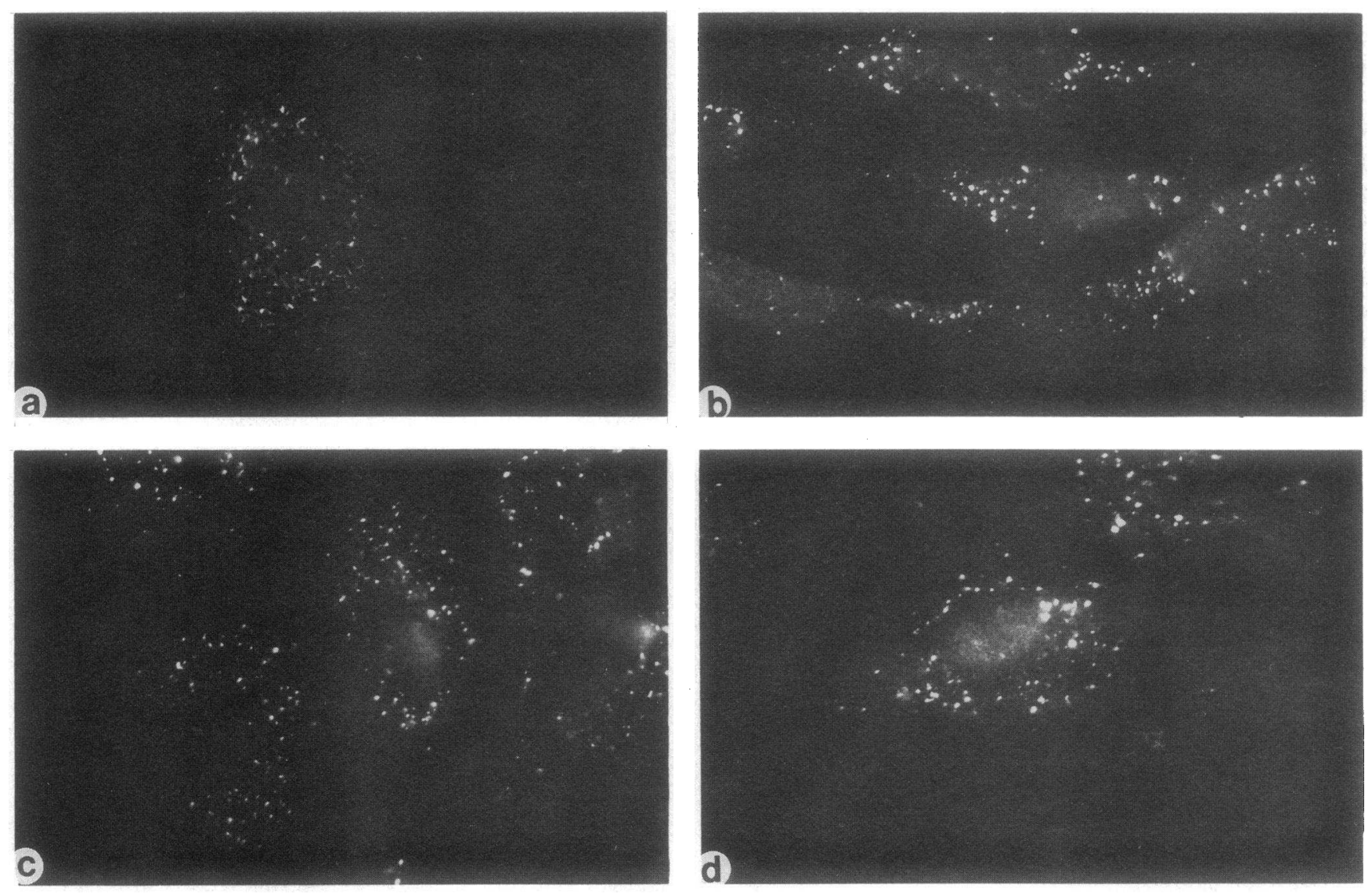

Figure 1. Localization of PMP70 in cells of patients with peroxisome-deficient disorders. Cells grown on coverslips were fixed, treated with Triton $\mathrm{X}-100$, and subjected to indirect immunofluorescence. The permeabilized cells were first incubated with rabbit antibodies against PMP70 and in the second step with goat anti-rabbit antibodies coupled to FITC. Displayed are control fibroblasts $(a)$, P2 $(b)$, P3 $(c)$, and P4 $(d)$ cells. Similar patterns of PMP70 localization were seen for P1, P5, P6, P7, and P8 (data not shown). $\times 500$.

of the patient cell lines contains peroxisome ghosts. In comparison to the appearance of normal peroxisomes, the PMP70-containing vesicles of cells from patients exhibited an enlarged size, increased staining, and lower abundance. These abnormal properties of peroxisome ghosts have been described repeatedly in previous studies (15-19).

Furthermore, we had to show that the import assay, which was originally developed for permeabilized CHO cells (25), was also applicable for fibroblast cell lines and that the import of proteins into peroxisomes was stimulated by cytosolic factors. $\mathrm{CHO}$ cells and control fibroblasts $(\mathrm{C})$ were grown on coverslips, permeabilized with $2.0 \mathrm{U} / \mathrm{ml} \mathrm{SLO}$, and subsequently incubated for $45 \mathrm{~min}$ with HSA-SKL, an artificial substrate for the peroxisomal import machinery $(24,25)$, in the presence or absence of external cytosol in form of rabbit reticulocyte lysate (also referred to as wild type cytosol). In CHO cells (Fig. 2, a and $b$ ), as well as in control fibroblasts (Fig. 2, $c$ and $d$ ), the import of HSA-SKL into peroxisomes depended on the addition of external cytosol.

These results showed that the import assay could be used for analyzing peroxisomal protein import in human fibroblast cell lines and confirmed the cytosol dependence of protein import.

In the same way, fibroblasts from eight patients belonging to six complementation groups were permeabilized with 2.0
$\mathrm{U} / \mathrm{ml}$ SLO and incubated with HSA-SKL in presence of externally added cytosol in form of rabbit reticulocyte lysate. A vesicular accumulation of HSA-SKL was not detectable in the vast majority of the cells in any of the analyzed cell lines classified as group A disorders (Fig. 3 and Table I). However, a few cells displaying a vesicular localization of HSA-SKL were observed in each of the cell lines (not shown). These cells accounted for $<1-5 \%$ of the cell population.

Our results show that each of the cell lines displays a deficiency in the import of SKL-containing proteins into peroxisomes. Furthermore, since the addition of wild type cytosol could not restore import, the molecular defect appears to be organelle associated.

Cytosol prepared from cells derived from patients reconstitutes peroxisomal protein import in $\mathrm{CHO}$ cells. In addition to the data presented above, we wanted to address whether cytosol from cells of patients is functional in stimulating peroxisomal protein import. We prepared cytosol from each of the cell lines. CHO cells were permeabilized with SLO under conditions where endogenous cytosol is washed out, and peroxisomal protein import depends on the addition of external cytosol. The permeabilized cells were subsequently incubated with HSASKL in presence of cytosol prepared from each of the human cell lines. We observed that cytosol from each of the eight cell lines from patients was functional in the reconstitution of per- 

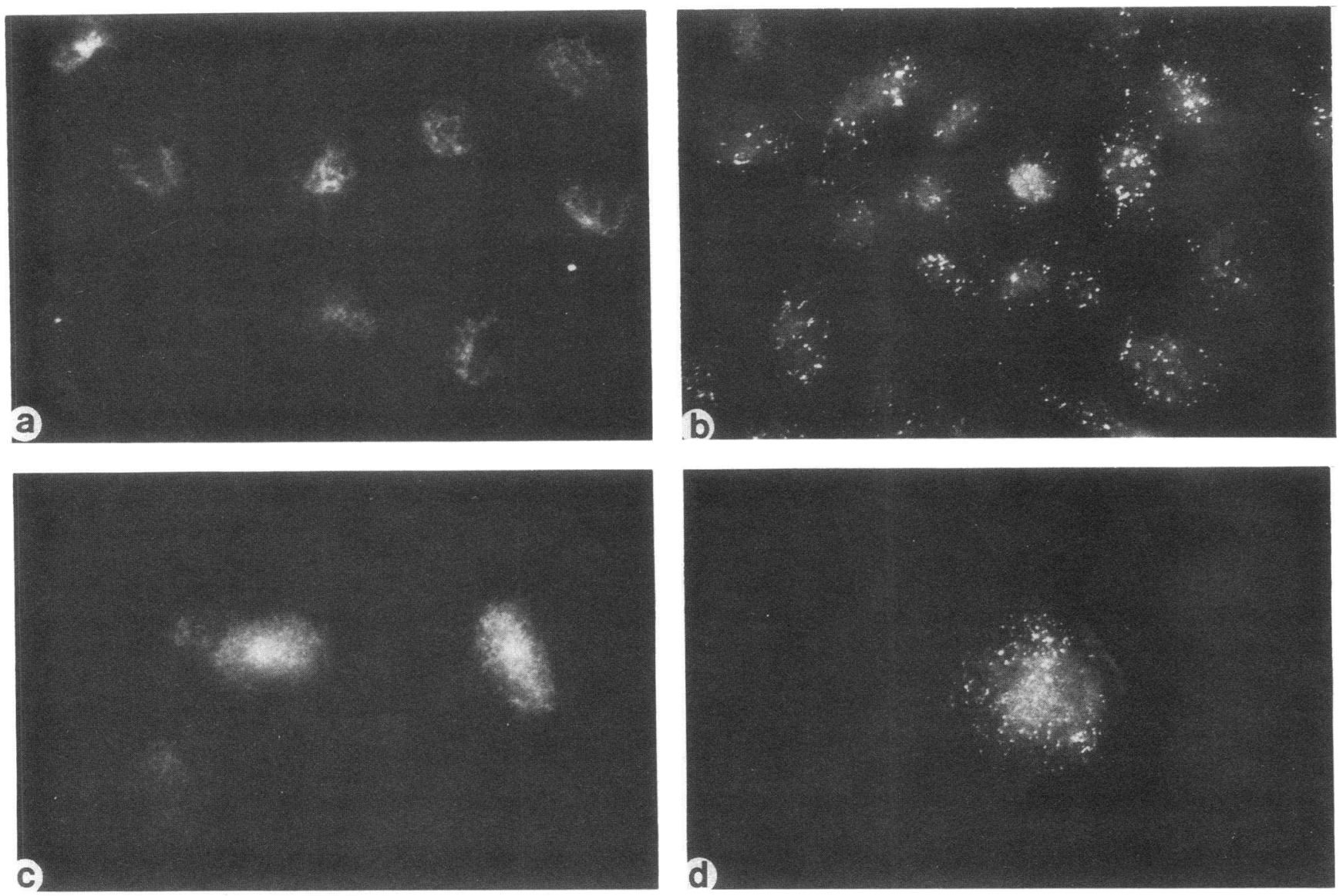

Figure 2. Cytosol dependence of peroxisomal protein import in SLO-permeabilized cells. CHO cells ( $a$ and $b$ ) and human control fibroblasts ( $c$ and $d$ ) were grown on coverslips to near confluency, permeabilized with $2.0 \mathrm{U} / \mathrm{ml} \mathrm{SLO}$, and incubated for $45 \mathrm{~min}$ with HSA-SKL in transport buffer supplemented without ( $a$ and $c$ ) or with ( $b$ and $d$ ) external cytosol in form of rabbit reticulocyte lysate. Subsequently the cells were washed, fixed, treated with Triton X-100, and subjected to indirect immunofluorescence. The cells were first incubated with rabbit antibodies against HSA and in the second step with goat anti-rabbit antibodies coupled to FITC. $\times 500$.

oxisomal protein import (Fig. 4 and Table I). Thus, these results provide direct evidence that the molecular defect preventing import of SKL-containing proteins into peroxisomes of cells from patients is not a soluble cytosolic factor.

\section{Discussion}

Cells of patients with generalized peroxisomal dysfunctions are characterized by the absence of normal peroxisomes. Instead, they contain membrane ghosts that are devoid of most matrix proteins but include, in certain cases, thiolase. This suggested that the underlying defect is the inability to import certain classes of matrix proteins. Different classes of peroxisomal proteins are delivered to the organelle matrix as the consequence of distinct PTSs of which, so far, two different types are known. The finding that two different ZS cell lines (groups 1 and 4) microinjected with SKL proteins were unable to import these substrates into their peroxisome ghosts (24) indicated that the defect may affect the class of PTS1-containing matrix proteins. However, complementation analysis showed heterogeneity for the genetic defects causing group A disorders $(12,13)$.

In this study, we have analyzed eight cell lines from patients with peroxisome-deficient disorders classified to six different complementation groups for $(a)$ the presence of peroxisome ghosts, $(b)$ the ability to import SKL-containing proteins into their peroxisome ghosts, and $(c)$ the presence of cytosolic factors stimulating peroxisomal protein import in a heterologous system.

Using anti-PMP70 antibodies, we showed that each of the cell lines contains peroxisome ghosts. SLO-permeabilized control fibroblasts imported the SKL substrate into peroxisomes when external cytosol was added. In contrast, each of the cell lines from patients with peroxisome-deficient disorders lacked the ability to import the SKL substrate into their peroxisome ghosts. As a rare event, a few cells with a vesicular localization of HSA-SKL were found. This observation is not surprising in view of other studies that show that $\leq 10 \%$ of cells from patients with peroxisome-deficient disorders contain normal peroxisomes $(17,22,27-29)$. Since the addition of external functional cytosol did not restore import in cells from patients with peroxisomal disorders, we propose defects in organelle-associated factors. This assumption was substantiated by the finding that cytosol prepared from each of these cell lines showed full activity in stimulating peroxisomal import in a heterologous system. We suggest that the molecular cause in each of the six complementation groups analyzed results from defects of factors associated with the peroxisomes, either as integral 

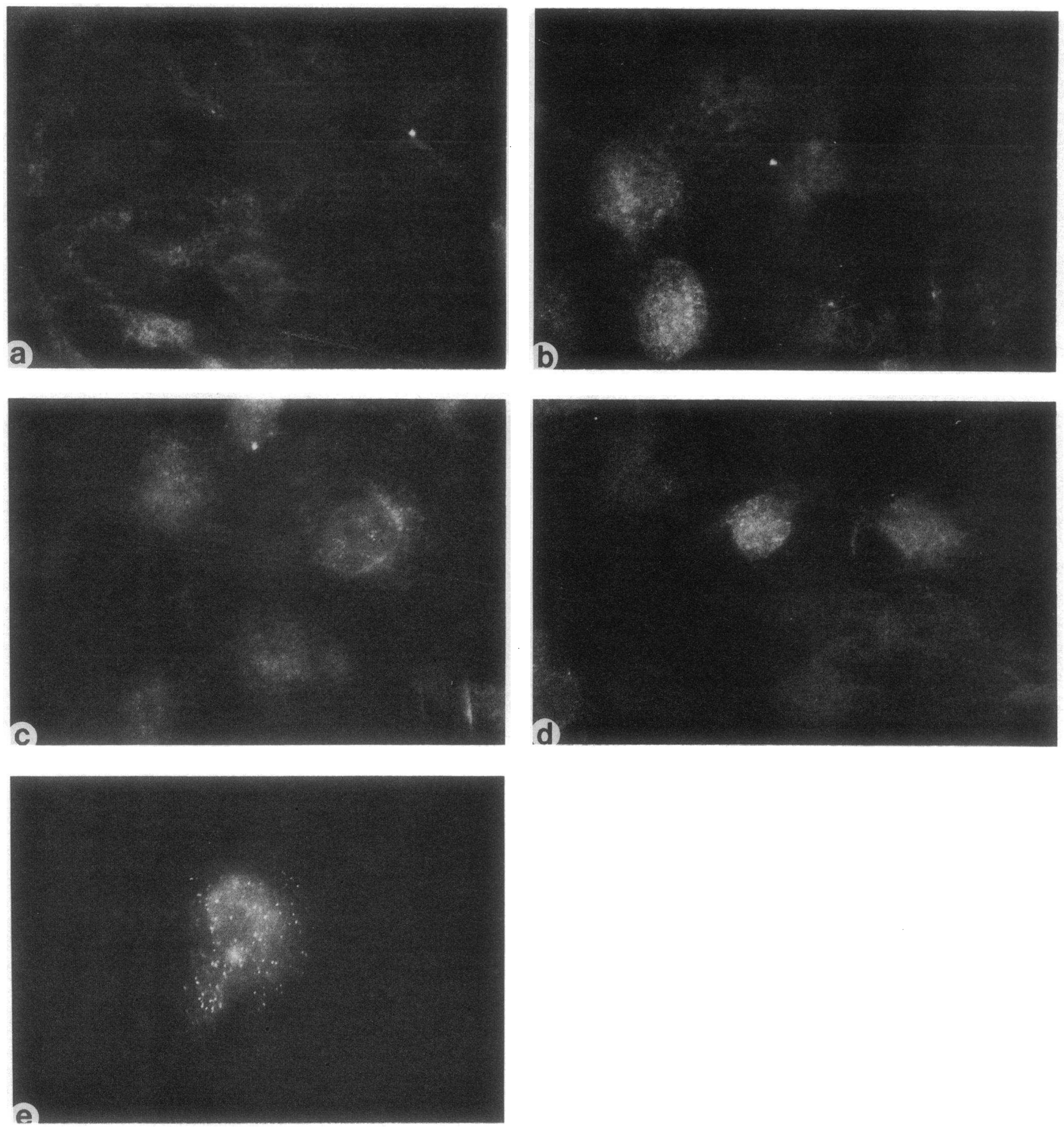

Figure 3. Cells from patients with peroxisome-deficient disorders are unable to import HSA-SKL into peroxisomes. Cells grown on coverslips were permeabilized with $2.0 \mathrm{U} / \mathrm{ml} \mathrm{SLO}$ and incubated with HSA-SKL in presence of external cytosol in the form of rabbit reticulocyte lysate as described in Fig. 2. Indirect immunofluorescence to analyze the localization of HSA-SKL was performed as described in Fig. 2. Displayed are the results obtained for $\mathrm{P} 2(a), \mathrm{P} 6(b), \mathrm{P} 7(c), \mathrm{P} 8(d)$ cells, and for control fibroblasts (e). Cells from P1, P3, P4, and P5 showed results similar to those shown for P2, P6, P7, and P8 (data not shown). $\times 500$.

membrane proteins, membrane-associated proteins, or intraperoxisomal factors. During the course of our investigations, the molecular defects of three ZS cell lines from two different complementation groups have been elucidated. Two ZS cell lines classified to group 1 (23) were shown to contain mutations in the PMP70 protein (30), and cells from a ZS patient from a new complementation group, not available for our studies, contain a mutation in a $35-\mathrm{kD}$ integral peroxisomal membrane protein (13). These results confirm our conclusion that organelle-associated defects impair the import of matrix proteins into peroxisomes of cells from patients with group A peroxisomal disorders. 

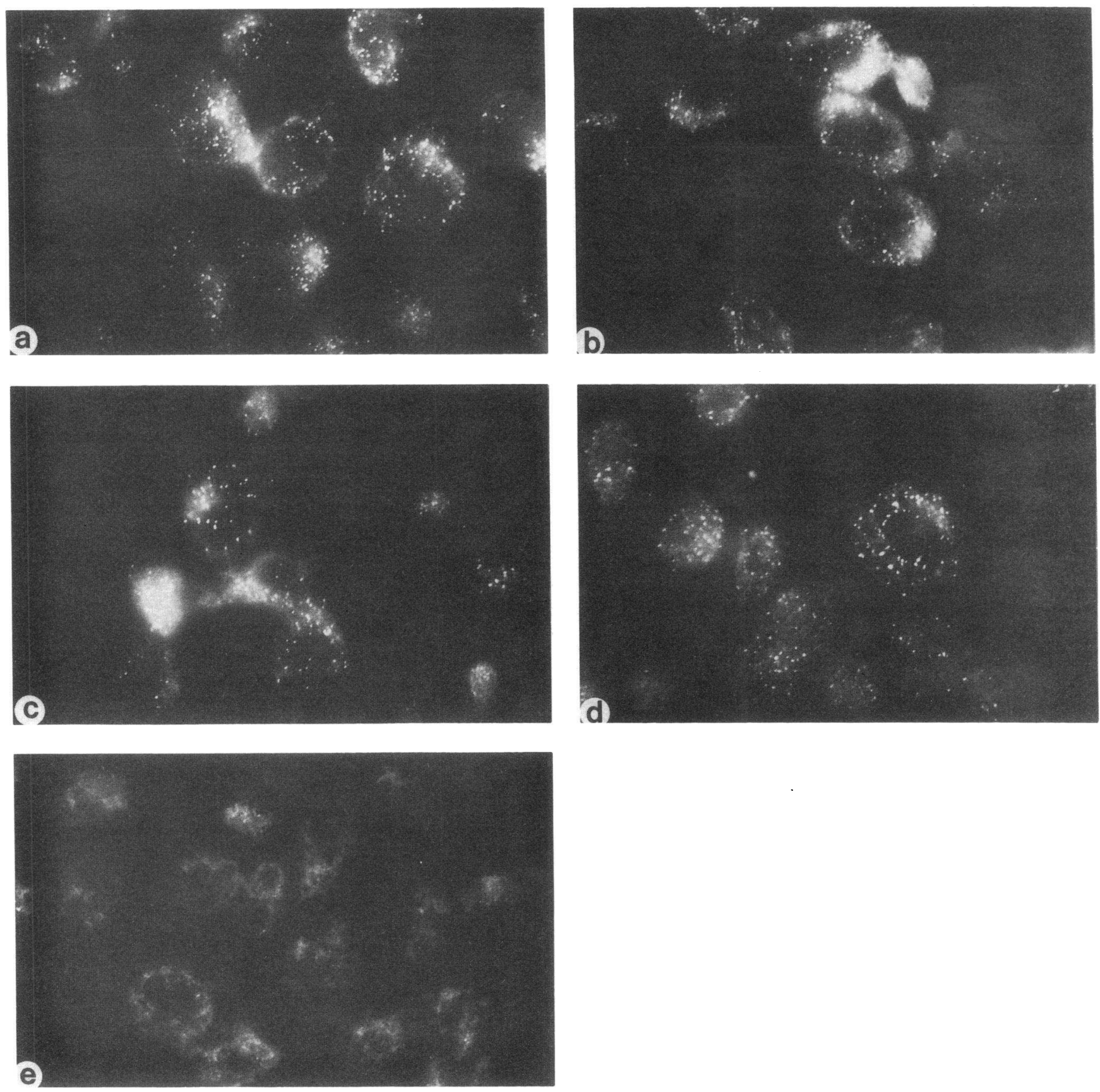

Figure 4. Cytosol prepared from cell from patients with peroxisome-deficient disorders reconstitutes peroxisomal protein import in SLO-permeabilized CHO cells. CHO cells were permeabilized with $2.0 \mathrm{U} / \mathrm{ml} \mathrm{SLO}$ and incubated with HSA-SKL in transport buffer supplemented with cytosol prepared from cells derived from patients $(a-d)$ or in absence of external cytosol (e). Indirect immunofluorescence to analyze the localization of HSA-SKL was performed as described in Fig. 2. Displayed are the results obtained for $\mathrm{CHO}$ cells incubated with cytosol prepared from control fibroblasts $(a), \mathrm{P} 5(b), \mathrm{P} 6(c), \mathrm{P} 8(d)$ cells, or in absence of external cytosol $(e)$. Cells from P1, P2, P3, P4, and P7 showed results similar to those shown for P5, P6, and P8 (data not shown). $\times 500$.

\section{Acknowledgments}

We thank Ann and Hugo Moser for supplying fibroblasts from human patients, Stephen Gould for providing the immortalized human fibroblast cell lines, and John Heyman for supplying the antibodies against PMP70.

This work was supported by a fellowship to $M$. Wendland from Deutsche Forschungsgemeinschaft and by a National Institutes of Health grant (DK 41737) to S. Subramani.

\section{References}

1. van den Bosch, H., R. B. H. Schutgens, R. J. A. Wanders, and J. M. Tager. 1992. Biochemistry of peroxisomes. Ann. Rev. Biochem. 61:157-197.

2. Gould, S. J., G. A. Keller, N. Hosken, J. Wilkinson, and S. Subramani. 1989. A conserved tripeptide sorts proteins to peroxisomes. J. Cell Biol. 108:1657-1664.

3. Swinkels, B. W., S. J. Gould, and S. Subramani. 1992. Targeting efficiencies of various permutations of the consensus C-terminal tripeptide peroxisomal targeting signal. FEBS (Fed. Eur. Biochem. Soc.) Lett. 305:133-136. 
4. de Hoop, M. J., and G. AB. 1992. Import of proteins into peroxisomes and other microbodies. Biochem. J. 286:657-669.

5. Swinkels, B. W., S. J. Gould, A. G. Bodnar, R. A. Rachubinski, and S. Subramani. 1991. A novel, cleavable peroxisomal targeting signal at the aminoterminus of the rat 3-ketoacyl-CoA thiolase. EMBO (Eur. Mol. Biol. Organ.) J. $10: 3255-3262$.

6. Osumi, T., T. Tsukamoto, S. Hata, S. Yokota, S. Miura, Y. Fujiki, M. Hijikata, S. Miyazawa, and T. Hashimoto. 1991. Amino-terminal presequence of the precursor of peroxisomal 3-ketoacyl-CoA thiolase is a cleavable signal peptide for peroxisomal targeting. Biochem. Biophys. Res. Commun. 181:947-954.

7. Roscher, A. A., and B. Rolinski. 1992. Peroxisomal disorders in man. Cell Biochem. and Funct. 10:201-207.

8. Heymans, H. S. A., R. B. H. Schutgens, R. Tan, H. van den Bosch, and P. Borst. 1983. Severe plasmalogen deficiency in tissue of infants without peroxisomes (Zellweger syndrome). Nature (Lond.). 306:69-70.

9. Moser, A. B., I. Singh, F. R. Brown III, G. I. Solish, R. I. Kelley, P. J. Benke, and $H$. W. Moser. 1984. The cerebrohepato-renal (Zellweger) syndrome: increased levels and impaired degradation of very long chain fatty acids and their use in prenatal diagnosis. $N$. Engl. J. Med. 310:1141-1146.

10. Danks, D. M., P. Tippett, C. Adams, and P. Campbell. 1975. Cerebro-hepato-renal syndrome of Zellweger: a report of eight cases with comments upon the incidence, the liver lesion, and a fault in pipecolic acid metabolism. J. Pediatr. 86:382-387.

11. Poulos, A., P. Sharp, and M. Whiting. 1984. Infantile Refsum's disease (phytanic acid storage disease): a variant of Zellweger's syndrome? Clin. Genet. 26:579-586.

12. Yajima, S., Y. Suzuki, N. Shimozawa, S. Yamaguchi, T. Orii, Y. Fujiki, T. Osumi, T. Hashimoto, and H. W. Moser. 1992. Complementation study of peroxisome-deficient disorders by immunofluorescence staining and characterization of fused cells. Hum. Genet. 88:491-499.

13. Shimozawa, N., T. Tsukamoto, Y. Suzuki, T. Orii, Y. Shirayoshi, T. Mori, and Y. Fujiki. 1992. A human gene responsible for Zellweger syndrome that affects peroxisome assembly. Science (Wash. DC). 255:1132-1134.

14. Goldfischer, S., C. L. Moore, A. B. Johnson, A. J. Spiro, M. P. Valsamis, H. K. Wisniewski, R. H. Ritch, W. T. Norton, I. Rapin, and L. M. Gartner. 1973. Peroxisomal and mitochondrial defects in the cerebro-hepato-renal syndrome. Science (Wash. DC). 182:62-64.

15. Santos, M. J., T. Imanaka, H. Shio, M. Small, and P. B. Lazarow. 1988. Peroxisomal membrane ghosts in Zellweger syndrome-aberrant organelle assembly. Science (Wash. DC). 239:1536-1538.

16. Santos, M. J., T. Imanaka, H. Shio, and P. B. Lazarow. 1988. Peroxisomal integral membrane proteins in control and Zellweger fibroblasts. J. Biol. Chem. 263:10502-10509.

17. Wiemer, E. A. C., S. Brul, W. W. Just, R. van Driel, E. Brouwer-Kelder, M. van den Berg, P. J. Weijers, R. B. H. Schutgens, H. van den Bosch, A. W. Schram, et al. 1989. Presence of peroxisomal membrane proteins in liver and fibroblasts from patients with the Zellweger syndrome and related disorders: Evidence for the existence of peroxisomal ghosts. Eur. J. Cell Biol. 50:407-417.

18. Gärtner, J., W. W. Chen, R. I. Kelly, S. J. Mihalik, and H. W. Moser 1991. The 22-kD peroxisomal integral membrane protein in Zellweger syndrome. Presence, abundance and association with a peroxisomal thiolase precursor protein. Pediatr. Res. 29:141-146.

19. Santos, M. J., S. Hoefler, A. B. Moser, H. W. Moser, and P. B. Lazarow. 1992. Peroxisome assembly mutations in humans: Structural heterogeneity in Zellweger syndrome. J. Cell. Physiol. 151:103-112.

20. Balfe, A., G. Hoefler, W. W. Chen, and P. A. Watkins. 1990. Aberrant subcellular localization of peroxisomal 3-ketoacyl-CoA thiolase in Zellweger syndrome and rhizomelic chondrodysplasia punctata. Pediatr. Res. 27:304-310.

21. van Roermund, C. W. T., S. Brul, J. M. Tager, R. B. H. Schutgens, and R. J. A. Wanders. 1991. Acyl-CoA oxidase, peroxisomal thiolase and dihydroxyacetone and phosphate acyltransferase: Aberrant subcellular localization in Zellweger syndrome. J. Inher. Metab. Dis. 14:152-164.

22. Suzuki, Y., N. Shimozawa, S. Yajima, T. Orii, S. Yokota, Y. Tashiro, T. Osumi, and T. Hashimoto. 1992. Different intracellular localization of peroxisomal proteins in fibroblasts from patients with aberrant peroxisome assembly. Cell Struct. Funct. 17:1-8.

23. Roscher, A. A., S. Hoefler, G. Hoefler, E. Paschke, F. Paltauf, A. Moser, and H. Moser. 1989. Genetic and phenotypic heterogeneity in disorders of peroxisome biogenesis. A complementation study involving cell lines from 19 patients. Pediatr. Res. 26:67-72.

24. Walton, P. A., S. J. Gould, J. R. Feramisco, and S. Subramani. 1992. Transport of microinjected proteins into peroxisomes of mammalian cells: inability of Zellweger cell lines to import proteins with the SKL tripeptide peroxisomal targeting signal. Mol. Cell. Biol. 12:531-541.

25. Wendland, M., and S. Subramani. 1993. Cytosol-dependent peroxisomal protein import in a permeabilized cell system. J. Cell Biol. 120:675-685.

26. Kamijo, K., S. Taketani, S. Yokota, T. Osumi, and T. Hashimoto. 1990. The 70-kDa peroxisomal membrane protein is a member of the $\mathrm{Mdr}$ (P-glycoprotein)-related ATP-binding protein superfamily. J. Biol. Chem. 265:4534-4540.

27. Goldfischer, S., J. Collins, I. Rapin, B. Coltoff-Schiller, C. H. Chang, M. Nigro, V. H. Black, N. B. Javitt, H. W. Moser, and P. B. Lazarow. 1985. Peroxiso$\mathrm{mal}$ defects in neonatal-onset and $\mathrm{X}$-linked adrenoleukodystrophies. Science (Wash. DC). 227:67-70.

28. Arias, J. A., A. B. Moser, and S. L. Goldfischer. 1985. Ultrastructural and cytochemical demonstration of peroxisomes in cultured fibroblasts from patients with peroxisomal deficiency disorders. J. Cell Biol. 100:1789-1792.

29. Wiemer, E. A. C., M. Out, A. Schelen, R. J. A. Wanders, R. B. H. Schutgens, H. van den Bosch, and J. M. Tager. 1991. Phenotypic heterogeneity in cultured skin fibroblasts from patients with disorders of peroxisome biogenesis belonging to the same complementation group. Biochim. Biophys. Acta. 1097:232-237.

30. Gärtner, J., H. Moser, and D. Valle. 1992. Mutations in the 70K peroxisomal membrane protein gene in Zellweger syndrome. Nature Genet. 1:16-23. 